\title{
BIBLIOTHEKARISCH-INFORMATIONSWISSENSCHAFTLICHES RÄTSEL
}

Die Positionen der gesuchten Begriffe müssen selbst herausgefunden werden; einige Buchstaben sind bereits vorgegeben, um diese Aufgabe zu erleichtern.

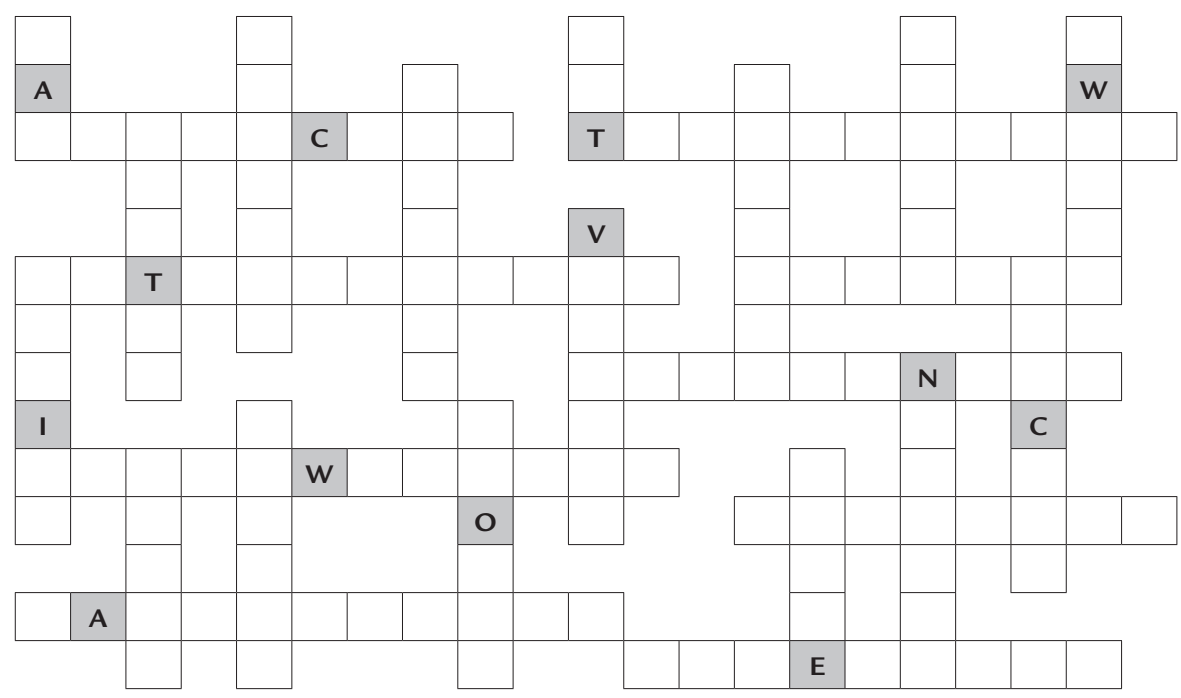


Form des Zusammenschlusses von Bibliotheken

Früherer US-amerikanischer Softwareentwickler (... Utilities, ...Commander)

Sprachliche Formen kommunikativer Handlungen, schreibbare

Sprachinformationen

Kommunikationsmittel, Datenspeicher

Sammlung von Audiodokumenten

Einzelne Facettenausprägung

(Facettenklassifikation)

Nautischer Vorläufer von

Protokolldateien

Wichtige bibliothekarische Tätigkeit

Gemeinsame Urheber eines

literarischen Werkes

Indexierungssystem von Derek Austin

Kontrolle, Prüfung (z.B. einer Datei)

Kunst der Gestaltung von

Druckerzeugnissen

Englische „Schwester" der Bibliothek
Kopfzeile, Dateikopf

Hochleistungsnetzwerk für die

Schweizer Wissenschaft

Wichtiger Thesaurus für Kunst und

Architektur (Abk.)

Methodische Vermittlung von

Kenntnissen und Fertigkeiten

Die in einer Datensammlung abgelegte Information

Frühere Bildschirmtechnologie (Kathodenstrahlröhre, Abk.)

Bibliotheksaffiner Handwerker

Zusammengehörende Menge von

Daten innerhalb einer Datei

Anpassen der Textzeilen an das

Seitenlayout

Grammatische Zählform

(Singular bzw. Plural)

Pufferspeicher für wiederholte

Zugriffe auf Daten

Chronologisches Selbstzeugnis, literarische Gattung 


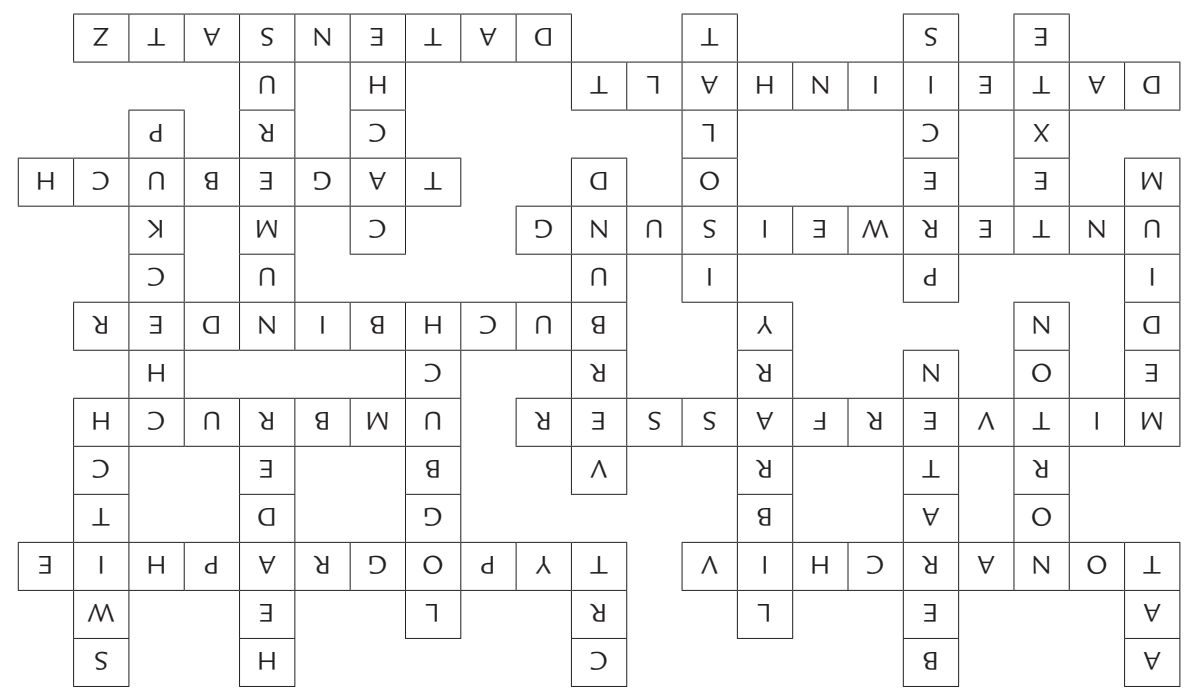

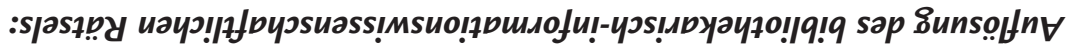

